\title{
Chemical Genomics: A Systematic Approach in Biological Research and Drug Discovery
}

\author{
X.F. Steven Zheng ${ }^{1 *}$ and Ting-Fung Chan ${ }^{2}$ \\ ${ }^{1}$ Department of Pathology and Immunology and ${ }^{2}$ Molecular \\ and Cellular Biology Program, Campus Box 8069 \\ Washington University School of Medicine \\ 660 South Euclid Avenue, St. Louis, Missouri 63110 USA
}

\begin{abstract}
The knowledge of complete sequences of different organisms is dramatically changing the landscape of biological research and pharmaceutical development. We are experiencing a transition from a trial-and-error approach in traditional biological research and natural product drug discovery to a systematic operation in genomics and target-specific drug design and selection. Small, cell-permeable and target-specific chemical ligands are particularly useful in systematic genomic approaches to study biological questions. On the other hand, genomic sequence information, comparative and structural genomics, when combined with the cutting edge technologies in synthetic chemistry and ligand screening/identification, provide a powerful way to produce target-specific and/or function-specific chemical ligands and drugs. Chemical genomics or chemogenomics is a new term that describes the development of target-specific chemical ligands and the use of such chemical ligands to globally study gene and protein functions. We anticipate that chemical genomics plays a critical role in the genomic age of biological research and drug discovery.
\end{abstract}

\section{Introduction}

The turn of this century marks significant progress in biology. We have advanced from knowing very little about our genetic makeup to now having complete knowledge of our genome. We are able to simultaneously analyze a network of proteins or genes. High throughput technologies have become essential to process enormous genomic information. In this regard, chemcal ligand-based approaches are especially powerful toward global understanding of gene and protein functions. Presently, the process of discovering target-specific chemical ligands using synthetic chemistry has become a practical means, which largely attributes to technological advances in targetspecific and diversity-based organic synthesis (Schreiber 2000), structure-based chemical ligand (or drug) design/

*For correspondence. Email zheng@pathology.wustl.edu; Tel. 314-747-1884; Fax. 314-747-2797. synthesis (Russell and Eggleston 2000) and new screening technologies such as small chemical compound (MacBeath et al. 1999) and protein microarrays (MacBeath and Schreiber 2000; Zhu et al. 2000; Haab et al. 2001). In this article, we will provide a detailed analysis of the current state of chemical genomics and its potential impact on biological and medical research, and pharmaceutical development.

\section{Chemical Biology or Genetics}

Since the seminal study of pea genetics by Mendal in 1865 , genetic analysis has been the benchmark for understanding gene or protein functions. In classical genetics or forward genetics, the genomic DNA of a model organism or cell is randomly mutagenized to generate large numbers of mutants, which are screened for a desirable phenotype or trait, such as alteration in growth, appearance or behavior. The phenotypes are then used to identify the responsible genes. A second type of genetic approach called reverse genetics, specifically mutates a known gene and studies the resultant phenotypes to understand the role(s) of the gene in the cell or organism. One major obstacle of traditional genetics is that mutations are usually constitutive. Mutations in essential proteins often lead to lethality at early life stage and make it impossible for subsequent study. Even if mutations do not cause lethality, the mutant organisms are often able to compensate for the loss of the gene, which obscures the effect of the original mutations. Modified genetic approaches have been developed to generate 'conditional alleles', in which the mutant gene only loses its function under restrictive conditions such as higher temperatures for the temperature-sensitive alleles (ts) or the presence of the Cre recombinase for the Cre/ loxP system (Lewin 1997). However, these approaches require complex genetic manipulation, which is often tedious and time-consuming. Moreover, they are based on blockage of steps leading to translation, which make them ineffective toward studying proteins with long halflives.

Over the past two decades, small chemical compounds have greatly enhanced our ability to delineate complex biological pathways and processes. They can rapidly penetrate into the cells, bind to their target proteins and create loss-of-function (or gain-of-function) phenotypes. In recent years, drug discovery has shifted from predominantly screening for natural products to targetoriented synthesis/screening of chemical ligands, which in large part is due to the realization that targeting the disease-causing genes/proteins and biological pathways is fundamentally important for successful development of highly effective drugs. This has promoted a close interaction between molecular biologists and synthetic chemists. As a result, an interphase between chemistry and biology called chemical biology or chemical genetics has come of 
age (Schreiber 1998). More comprehensive analysis of chemical genetics can be found in several recent reviews (Crews and Splittgerber 1999; Stockwell 2000; Alaimo et al. 2001). In a typical chemical genetics approach, a cell permeable, target-specific chemical ligand is added to the cells of interest, which binds to and causes loss-of-function or gain-of-function of its protein target. Chemical ligands may bind to the enzyme's catalytic site by mimicking natural substrates of the enzyme, as exemplified by the drug lovastatin/mevinolin. Lovastatin interacts with the catalytic site of hydroxymethylglutaryl (HMG)-CoA reductase and inhibits its enzymatic activity (Alberts et al. 1980). The ligand can also interact with a key regulatory domain as in the case of phorbol ester, which resembles diacylglycerol, a natural protein kinase C (PKC) activating lipid molecule (Newton 1997). Chemical ligands can be easily administrated at any time during the cell cycle or developmental stages, and any desired location of the cell or organism. Therefore, chemical ligands pose unparalleled temporal and spatial control over their protein targets.

\section{Forward and Reverse Chemical Genetics}

The so-called forward chemical genetics describes how natural products (a compound of natural origin) or a pool of synthetic compounds is screened for desired phenotypes, such as inhibition of tumor growth in vitro. Once a biologically active compound is identified, effort is shifted toward identification of the drug target(s). Classical examples include the proteasome inhibitor lactacystin and the immunosuppressant rapamycin (Schreiber 1991). Both drugs are microbial natural products that inhibit cell proliferation and interfere with normal cellular functions (Martel et al. 1977; Omura et al. 1991). Lactacystin specifically binds to and inhibits the $20 \mathrm{~S}$ proteasome (Fenteany et al. 1995). Rapamycin, when associated with the immunophilin FKBP-12, binds to and inhibits the target of rapamycin protein (TOR) (also called FKBP12rapamycin-associated protein or FRAP) (Cafferkey et al. 1993; Kunz et al. 1993; Brown et al. 1994; Sabatini et al. 1994; Sabers et al. 1995). Knowledge of the target proteins has advanced chemical genetics to a stage that parallels the classical reverse genetics, i.e., the use of the compound to study the biological functions of the drug target protein. For example, as a result of the use of lactacystin, the proteasome is found to be important for diverse biological pathways and processes, including antigen presentation, cell cycle control and cell fate determination (Fenteany and Schreiber 1998). Similarly, studies using rapamycin found that TOR regulates a number of proteins such as ribosomal S6 kinase 1 (S6K1) (Chung et al. 1992; Kuo et al. 1992) and the transcription factor Gln3 (Beck and Hall 1999; Cardenas et al. 1999; Hardwick et al. 1999; Bertram et al. 2000). Target-specific chemical ligands have gained great popularity in biological research in recent years. For instance, there are nearly 2,000 papers citing the use of the MAP kinase kinase (MKK) inhibitor PD98059 and over 1,500 papers reporting the use of the phosphoinositide 3kinase (PI-3K) inhibitor wortmannin (Hunter 2000).

\section{Protein Engineering in Chemical Genetics}

Although there is significant advancement in chemical ligand synthesis and screening, there are still a relatively small number of target-specific chemical ligands available. An alternative approach has been developed to use a combination of protein and chemical engineering to modulate the functions of proteins and genes (Bishop et al. 2000). An early example of this is the use of a synthetic chemical dimerizer, called FK1012 that is derived from FK506 with two FKBP12-binding moieties. FK1012 has been used to induce the interaction between the protein of interest that is fused to FKBP12, thereby altering the activity of the protein (Spencer et al. 1993). Variations of this approach with a single compound such as rapamycin that has two distinct protein-binding surfaces can provide higher specificity and more flexibility for such approaches (Amara et al. 1997). Another approach takes advantage of an already existing small molecule ligand or substrate of an enzyme. By a so-called "bump-and-hole" approach, one can add an extra space-filling group onto the ligand (bump) and then create a cavity (hole) in the ligand-binding site of the enzyme. Only the engineered enzyme, but not the native enzyme modified ligand can recognize the modified ligand. Belshaw et al. first described this approach in the study of cyclophilin and its ligand cyclosporin A (Belshaw et al. 1996). Shotkat and colleagues subsequently used a similar approach to study protein kinases. Protein kinases are highly conserved in their catalytic domains, making it difficult to develop highly specific inhibitors to each individual kinase. Shokat and colleagues mutated the ATP binding site of $v$-Src such that the engineered v-Src uniquely accepted $N^{6}$-(cyclopentyl) ATP, an ATP analog to catalyze normal protein phosphorylation (Shah et al. 1997). In contrast, $N^{6}$-(cyclopentyl) ATP is not accepted by the unmodified $v$-Src or other protein kinases. Using a variation of the above strategy, the same group also created allelespecific inhibitors of engineered protein kinases (Bishop et al. 1998). These inhibitors specifically inhibit the modified protein kinases, but not the wild type, endogenous kinases. These chemical ligands can be used to effectively turn on and off engineered proteins.

\section{Development of Target-Specific Chemical Ligands}

Target-specific chemical ligands are pivotal for studying biological questions and drug development. Natural products have been traditionally the source for novel ligand screening and discovery, primarily because of their unparalleled range in mode of action and chemical diversity (for a recent review on natural products in anticancer therapy, see da Rocha et al. 2001). In recent years, alternative strategies have become more practical, which is largely due to significant technological advances in organic synthesis, computational power and the increased information on protein sequences and structures. It is now possible to streamline chemical ligand design, synthesis and selection leading to successful drug development (illustrated in Figure 1). 


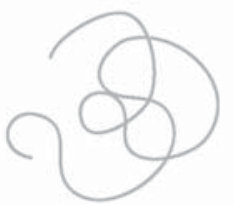

Amino acids sequence

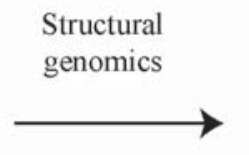

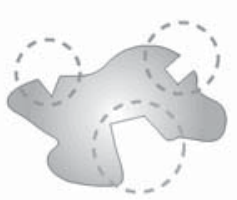

Target sites identification
Target-oriented

design of

lead compound

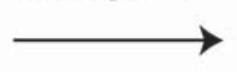

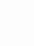

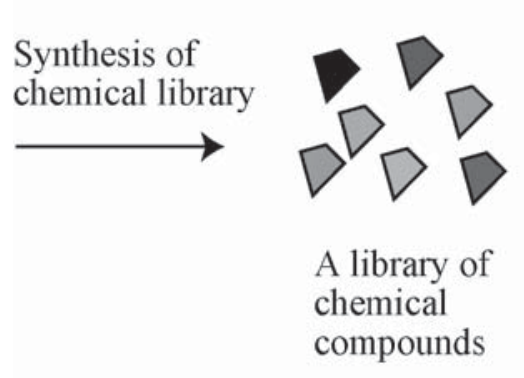

A library of chemical compounds

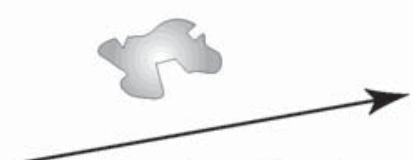

Screen for affinity for the target protein

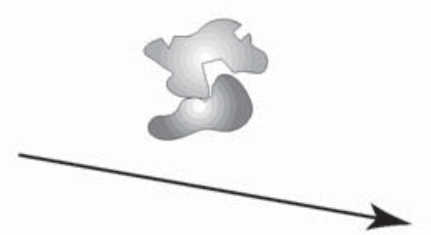

Screen for biological activity of a target such as proteinprotein interaction
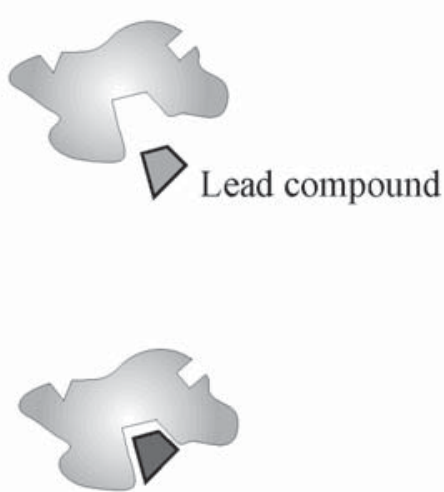

Chemical ligand that binds to the target protein

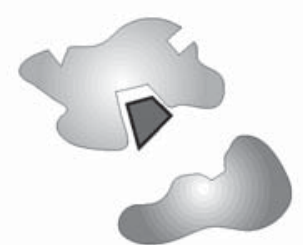

Chemical ligand disrupting interacting proteins

Figure 1. A typical streamline of design, synthesis and selection of chemical ligands

Three-dimensional (3D) structural information of the interested protein can lead to identification of important target sites for chemical ligands, which are used to design the lead compound(s). A library of derivatives of the lead compounds is then synthesized by combinatorial chemistry and screened by in vitro and in vivo methods such as affinity for the interested protein and a biological activity associated with the protein.

\section{Combinatorial and De Novo Approaches in Chemical Ligand Synthesis}

Combinatorial organic synthesis has increasingly been used to generate small molecule libraries for ligand screening and drug discovery. It stems from the original solid-phase oligonucleotide and peptide synthesis, which provides a way to synthesize and purify peptides with defined sequences (Frank et al. 1983; Geysen et al. 1984). Such a technique also allows synthesis of oligonucleotides or peptides of all possible permutations of nucleotides or amino acid residues. This concept has been extended to other small molecules as well. Polycyclic compounds and natural product derivatives that mimic biologically active molecules (biomimetics) are among the most common types of structures that have been made in this fashion (Schreiber 2000; Gray 2001). This is because small molecule libraries based on a known lead compound (also known as focused libraries) often provide a better chance in finding new biologically active molecules.

Another concept in chemical ligand synthesis that has emerged in recent years is to change the chirality of the compounds. Biological molecules often contain chiral or asymmetric carbon atoms, at which the carbon atom is bonded to four different moieties. Such molecules exist in two forms, known as enantiomers. These molecules have opposite effect in rotating plane-polarized light, and their three-dimensional structures are different and therefore possess different biological properties. The best example is the twenty naturally occurring amino acids. Living organisms such as yeast can only metabolize L-amino acids, which rotate plane-polarized light to the left, but not $\mathrm{D}$-amino acids, which rotate plane-polarized light to the right. Examples of chirality and its application in chemical ligand synthesis and design are reviewed in detail elsewhere (Hutt and O'Grady 1996; Vuylsteke 2000).

Lead compounds (de novo design) are pivotal to develop a meaningful chemical library that can eventually yield biologically active compounds. To develop successful lead compounds against diverse protein targets, a designer approach is needed. This is when the in silico approach comes into play, owning to significant advances in computational power and the development of artificial intelligence (AI). Databases that detail known molecular structures with their corresponding functions form the basis for the so-called Quantitative Structure-Activity Relationship 
(QSAR) approach. QSAR and its variants provide the statistical framework for analysis of virtual libraries of small molecules (Klebe 2000). Computer programs and algorithms have been developed to guide every major step in de novo design. Programs such as GASP (Génération Automatique de Structures Polycycliques) (Barone et al. 2001), which generates a virtual library of a large number of polycyclic structures with the given parameters, can help expand the diversity and complexity of potential chemical ligands. Another area worthy of attention is the use of Darwinian molecular evolution in ligand design. It dates back to 1990 when Tuerk and Gold looked for RNA ligands that bind to bacteriophage T4 DNA polymerase by using Systematic Evolution of Ligand by Exponential Enrichment (SELEX) (Tuerk and Gold 1990). This concept has inspired the development of genetic algorithms (GA) and simulated molecular evolution in chemical ligand design. On the basis of existing biological screening results, GAs are used to simulate the docking of chemical ligands to the binding sites of their target proteins, and to optimize and select compounds with desired properties without the need to actually synthesize and test all possible conformations (Singh et al. 1996; lllgen et al. 2000).

The Impact of Comparative Genomics and Structural Genomics in Chemical Ligand Design

Comparison of whole genome sequences of different organisms is a powerful tool for identifying essential components of cellular processes, understanding the genome architecture as well as reconstructing the evolutionary events. Tatusov et al. reported the comparison of seven complete genomes in five major phylogenetic lineages (Tatusov et al. 1997), and this has now expanded to 44 complete genomes in 30 major phylogenetic lineages (http://www.ncbi.nlm.nih.gov/COG). The clusters of orthologous groups (COGs) allow information flow from well-studied model organisms to poorly characterized ones. In recent years, comparative genomics in mammals has improved the resolution of genetic maps in human and other model organisms and identified many human disease genes in other mammalian models (reviewed in O'Brien et al. 1999). Comparative genomics in more evolutionarily distant organisms allows the identification of the core proteome, the set of proteins that is unique to individual species, as well as components that are highly conserved in a specific cellular or developmental process (Rubin et al. 2000; Venter et al. 2001). Aravind et al. reported a comparative analysis of the apoptotic molecular machinery in human, Drosophila melanogaster and Caenorhabditis elegans (Aravind et al. 2001). They noticed that relative to the invertebrates in human there is a general increase in the number of apoptosis-associated proteins and in the complexity of protein domains involved. Knowing the intrinsic difference in any cellular process between human and other species will better help us to evaluate how applicable the information we obtained from other model organisms is to humans, and to choose the correct target proteins for drug discovery.

Information obtained from comparative genomic studies is having a significant impact on the field of structural biology. It is clear that protein three-dimensional structures can greatly facilitate the drug discovery process. In many cases the availability of crystal structure data or predicted structures not only help us to better understand the catalytic activity of the protein, but also show us the mechanism of how such a protein interacts with other proteins as well as the allosteric actions or conformational changes involved. The continuous improvement in computation power and development of new bioinformatic tools have laid the foundation for high-throughput $X$-ray crystallography and nuclear magnetic resonance (NMR) spectroscopy in protein structure determination (Stevens 2000; Stevens et al. 2001). This structural genomics approach is aimed at systematically generating both experimental protein structures and unique structural folds (Burley 2000). In order to provide a structure for each family of proteins using this high-throughput analysis, efforts have been made to ensure proper protein target selection (Brenner 2000). In particular, proteins that are inappropriate for this approach or redundant are being excluded. Protein sequences of unknown three-dimensional structure are modeled by structure prediction and submitted before the meeting. At the same time the three-dimensional structures of these sequences are being determined by X-ray crystallography and NMR spectroscopy. Results from these two approaches are then compared to further refine the methods. Such a process will ensure the quality of the structures generated by structural genomics.

\section{High Throughput Screening Technologies in Drug Discovery}

Chemical ligand discovery through natural-product screening has spearheaded therapeutics development and biological discovery for many years (Bull et al. 2000). As discussed earlier, synthetic chemistry is now capable of producing a large number of diversified chemical compounds, which require high throughput screening (HTS) technologies for selection of specific ligands. One prominent example of HTS is the in vitro cell line-screening project (IVCLSP) under the Developmental Therapeutics Program (DTP) at the National Cancer Institute (NCl)(http:/ /dtp.nci.nih.gov/index.html), which uses 60 human cancer cell lines ( $\mathrm{NCl} 60)$ for the drug discovery screen. About 5,000 out of 60,000 potential anticancer compounds screened are found to have anti-cancer activity. After eliminating closely related compounds and the ones with known mechanisms of action, the remaining 1,200 are selected for further testing. Another example of cell-based HTS is the receptor selection and amplification technology (R-SAT), which produces a signal (usually in terms of changes in the levels of B-galactosidase) whenever a test compound interacts with an expressed receptor, such as G-protein coupled receptors and nuclear receptors. In the presence of receptor activity, cells overcome contact inhibition and proliferate. The increase in cell number is translated into an increase in the level of $B$-galactosidase, whose level can be quantitatively measured using a spectrophotometer.

Stockwell et al. developed a miniaturized, whole-cell immunodetection system, called a "cytoblot", for high- 
throughput screening of biologically active molecules (Stockwell et al. 1999). In this study, a library of small molecules were screened based on their ability to inhibit of cell growth, which was monitored by following the DNA content using an anti-BrdU antibody. Similar experimental design is suitable for screening for compounds that interfere with other cellular events, such as phosphorylation of a particular disease-causing protein. This approach has allowed the recent discovery of an array of antimitotic agents, including a novel inhibitor of mitotic spindle bipolarity named monastrol (Mayer et al. 1999). Monastrol specifically inhibits the mitotic kinesin Eg5. Since all the existing microtubule drugs target tubulin, an inhibitor of the microtubule motor protein will be useful for studying microtubule structures and functions.

Many important cellular regulatory events are mediated by protein-protein interaction. A classical example is the pRB-E2F-DP tumor repressor complex (reviewed in Harbour and Dean 2000). Mutations in the pRB binding pocket can lead to defective protein-protein interaction and tumorigenesis. Therefore, disrupting the binding of two disease-causing proteins has become a focal point for drug development. In this respect, the yeast two-hybrid system can be of particular value. One strategy to screen for small molecules that can prevent interaction between the target protein and its binding partner is by using a reverse yeast two-hybrid system, in which the reporter gene URA3 is used (reviewed in Vidal and Endoh 1999). On the medium containing 5-fluoro-orotic acid (5-FOA), disruption of protein-protein interaction by a small molecule will block expression of the URA3 gene, thereby allowing cell growth. An attempt to screen for allosteric drugs that function by affecting protein conformation has also been reported recently (DeDecker 2000). Another example is the study of the tumor repressor p53. Tumorigenic mutations in p53 have been linked to overall destabilization of the protein conformation (Brachmann et al. 1998). Foster et al. reported the screening of a library of more than 100,000 molecules and identified 2 molecules that can stabilize the protein fold of p53 point mutants (Foster et al. 1999).

Like DNA, small chemical ligands can also be immobilized on a glass surface for in vitroligand screening (MacBeath et al. 1999). Knockaert et al. reported the use of such an approach in identifying intracellular targets of chemical inhibitors of the cyclin-dependent protein kinase (Knockaert et al. 2000). In this study, purvalanol B and its derivatives were immobilized on an agarose matrix, and cell extracts prepared from a diverse class of cell types and organisms were screened for proteins binding purvalanol $B$. This approach can easily be scaled up to include a small molecule library. Printing proteins on a glass surface can provide a way to assay for drug affinity for a large number of different proteins. Several groups have recently reported the development of protein microarrays for a variety of applications, such as identifying protein kinase substrates (Zhu et al. 2000), antibody screening (Lueking et al. 1999), screening for protein-protein interactions as well as protein targets for chemical probes (MacBeath and Schreiber 2000) and accurate measurement of protein abundance using antibody/antigen microarrays (Haab et al. 2001).

\section{Chemical Ligands and Systematic Study of gene and Protein Functions}

Given their unparalleled control of their target gene/protein, chemical ligands are particularly suitable in genomic study of gene/protein functions. They can be readily integrated into the existing genomic approaches and tools. A significant advantage of using chemical ligands is that there is no limit on the developmental stage of the organisms or the conditions the cells and organisms are in. In addition, chemical ligands can be easily used in high throughput analyses.

\section{Chemical Ligands and Gene Expression Profiling}

The most popular approach currently is to use chemical ligands to study the role of the drug target in the control of gene expression. High-density oligonucleotide or complementary DNA (cDNA) microarrays (collectively called DNA microarrays) immobilized on the surfaces of glass slides can be used to simultaneously analyze the expression of thousands of genes (Lockhart and Winzeler 2000). DNA microarrays have proven very useful in elucidating the functions of the drug targets involved in transcriptional control (Figure 2A). In such an approach, the cell, tissue or organism is treated with chemical ligands. mRNAs are prepared from the treated and untreated cell or organism, and then used to produce fluorescencelabeled cDNAs to hybridize DNA microarrays and generate gene expression profiles. By comparing the differences between the profiles before and after drug treatment, genes whose expression is modulated by the chemical ligands are then identified. These genes are further classified into pools based on similar functions or co-regulation in the cell. This information can often reveal specific transcription factors and other regulators for each gene pool, thereby allowing assembly of potential regulatory pathways involving the drug target. A nice example is provided by a recent study of yeast histone deacetylases (HDACs) (Bernstein et al. 2000). In that study, three yeast HDACs, HDA1, RPD3 and SIR2, were examined using the drug trichostatin A (TSA) and deletion of the genes. Hda1 and Rpd3, but not Sir2, are sensitive to TSA. The authors elegantly demonstrated that individual HDACs have specific roles in distinct transcriptional pathways as well as some limited overlapping functions. It is now realized that genes are regulated as networks. Many genes are co-regulated in response to unique cellular conditions. Efforts are being made to establish gene expression profile databases of regulatory proteins and transcriptional pathways. It is now possible to simultaneously compare the drug-induced profiles with the existing gene expression databases, thereby identifying relevant biological pathway(s) or functions for the drug target. For example, Hughes et al. used a compendium approach to compare the drug-induced expression profile to reference profiles of known cellular pathways (Hughes et al. 2000). 


\section{Chemical Ligands and Protein Profiling}

Proteomics or protein profiling is a field dedicated to studying the complete protein complement of a cell, tissue or organism. Posttranslational modifications play crucial roles in regulation of diverse cellular processes such as signal transduction, cell cycle control, development, cytoskeleton networks and metabolism. Common posttranslational modifications include phosphorylation (Hunter 2000), ubiquitylation (Hershko and Ciechanover 1998) and related polypeptide-dependent modifications (Hochstrasser 2000), acetylation/methylation (Sterner and Berger 2000; Rice and Allis 2001) and proteolytic processing (Mayer 2000). Even a single protein can undergo several different forms of modification. For example, histone, a major building block of the chromatin, is phosphorylated, acetylated and methylated (Giaccia and
Kastan 1998). Deregulation in any of these modifications can contribute to chromosomal and genome instability, which may contribute to genetic defects and cancer. Another important aspect of protein profiling is the study of controlled assembly of protein complexes. Dynamic changes in the components of these biological complexes often form the regulatory basis for their relevant cellular processes.

Small, cell-permeable chemical ligands are particularly powerful in linking a regulatory protein and posttranslational modification of its downstream targets. In a typical approach (Figure 2A), a chemical ligand is added to the cells, which leads to inhibition (or activation) of the regulatory protein. As a result, posttranslational modification(s) of its downstream targets is changed, which can be detected traditionally by two-dimensional (2D) gels as judged by each protein's unique charge and size (Moller et al. 2001),

\title{
A. Chemical ligands in gene expression and protein profilings
}

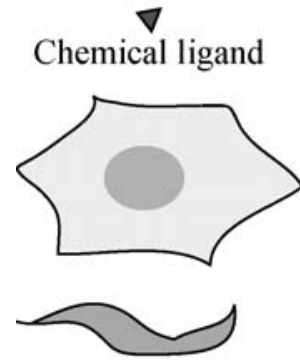

A cell or organism

\begin{abstract}
Preparation of
\end{abstract}
mRNA and

cDNA probes

Preparation of protein samples
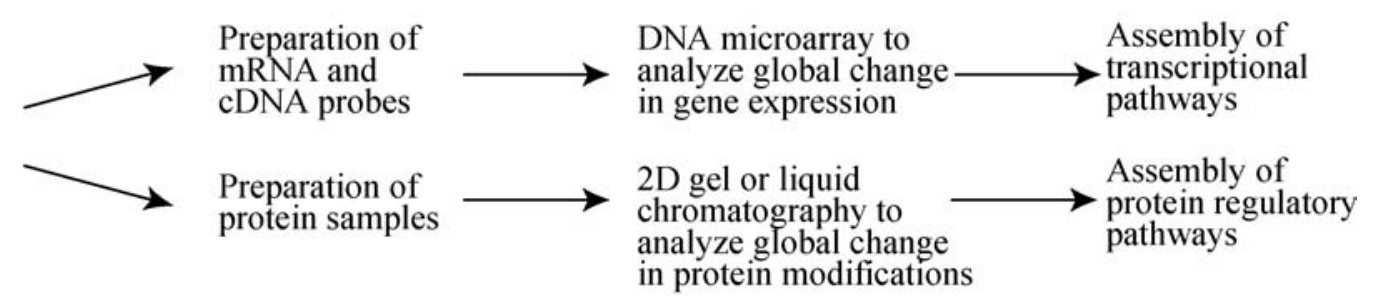

DNA microarray to

Assembly of analyze global change in protein modifications

\section{B. Chemical ligands in global genetic interaction study}

\author{
Chemical ligand
}

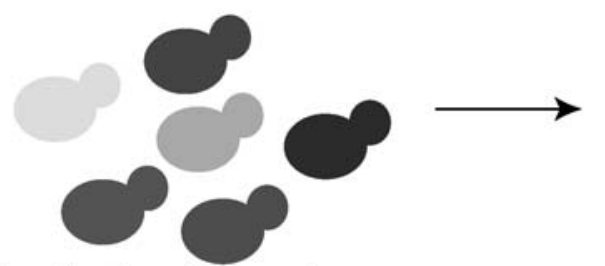

Selection of

mutants hypersensitive

or resistant to the drug

Assembly of global genetic pathways

A collection of genomic mutants

Figure 2. Chemical ligands and systematic study of gene and protein functions

A. Chemical ligands and global gene expression profiling and protein profiling

To study the role of a protein in global gene transcriptional control, a target-specific chemical ligand is used to modulate its activity. Total cellular mRNAs are extracted from the cells before and after treatment with the chemical ligand. Fluorescence-labeled cDNA are generated and used to hybridize a high-density DNA microarray. Comparing the expression profiles of the samples reveals the genes and the transcriptional pathways under the control of the drug target protein. Alternatively, total cellular proteins are prepared and analyzed for global changes in posttranslational modification by protein profiling technologies such as two-dimensional (2D) gel electrophoresis and liquid chromatography. This will allow assembly of biochemical pathway(s) controlling protein modifications. B. Chemical ligands and global study of genetic interactions

A collection of genomic mutants (cells or simple organisms) is assayed for their sensitivity to the chemical ligand of interest. Mutants hypersensitive or resistant to the drug can be determined by comparison of samples in the absence and presence of the drug. The genetic interaction network can then be assembled by pooling genes with similar functions. 
or liquid chromatography-based protein separation technologies, including the non-porous reversed-phase high-performance liquid chromatography (RP-HPLC) (Chong et al. 2001) and the two dimensional (2D) liquidphase separation method (Wall et al. 2000). Since these separation methods are based on the biochemical and biophysical properties of the polypeptides, each protein tends to have a unique profile (or migration pattern) that can be used for its identification. In the cases that separation alone cannot provide sufficient information about the protein, its identity can be further revealed by Mass spectrometry (Gygi and Aebersold 2000). When the protein has a change in modification, its unique profile also changes and can be used as the basis for further investigation based on the nature of the modification. For example, phosphorylation of a protein is easily reversed by phosphatase treatment in vitro. Moreover, phosphorylation-, ubiquitin- and acetylation/methylationspecific antibodies can be used to detect the nature of protein modifications. The above approaches apply to any type of modification. Alternatively, modified proteins can be directly captured and examined for their relative abundance under different conditions. Two recent reports described smart chemistry that allows selective modification of phosphopeptides or phosphoproteins within complex mixtures (Zhu et al. 2000; Oda et al. 2001). Modified peptides or polypeptides are then enriched by covalent or high affinity avidin-biotin coupling to immobilized supports, thereby allowing rapid analysis of phosphorylation events in cells. In a similar vein, modifications with ubiquitin, ubiquitin-like peptides, and methyl and acetyl groups can also be used as epitope tags to capture their modified proteins. In addition, antibodies with specificity toward modified peptides can be arrayed on microchips and used to detect changes in modification of individual proteins (Belov et al. 2001; Huang 2001). In any event, total cellular proteins still need to be compared under different conditions to ensure accurate measurement of a change in protein modification. These new proteinprofiling technologies can be easily integrated into chemical ligand-directed research.

\section{Chemical Ligands and Global Genetic Interaction Study}

Genetic interaction is a powerful way to study the relationship among genes (or proteins). If a gene acts in the same pathway or a parallel pathway with a second gene, its mutation may affect the phenotype(s) of a mutation in the second gene. Such secondary mutations lead to modification of phenotypes of the first mutations and are thus called modifier mutations, which allows identification of new components in the pathway(s) of a gene of interest. In an extreme case, two normally viable mutations, when combined, can generate a lethal phenotype, which is called synthetic lethality. Several genomic deletion projects have systematically generated deletion of individual genes in model organisms, including the budding yeast (Winzeler et al. 1999), the worms (Liu et al. 1999; Bargmann 2001), the fruit fly (Spradling et al. 1999) and the mouse (Coelho et al. 2000). This has made it possible to conduct global genetic interaction studies of the gene of interest. However, using the traditional targeted mutagenesis method is a formidable task even with budding yeast, the simplest eukaryotic organism, since one would need to generate the same mutation in 6,217 different mutants. With a chemical ligand, however, it is an easy and simple operation. One would simply add the drug to the 6,217 samples and then examine the subsequent phenotypes to identify genes whose mutations cause hypersensitivity or resistance to the drug. Since genes in the same biological pathway involving the drug target should confer drug sensitivity phenotypes to various degrees, such a chemical genomic screen should reveal most if not all of the genes in the pathway. The potential global genetic pathways or global genetic network can then be assembled by simply pooling genes with similar cellular functions (Figure 2B).

The screening process can be easily automated either as a 96-well plate-based assay or an oligonucleotide microarray-based assay that takes advantage of the internal barcodes to each deleted locus (Giaever et al. 1999). Giaever et al. demonstrated the feasibility of a genome-wide drug sensitivity screen by examining 233 yeast deletion strains to the drug tunicamycin (Giaever et al. 1999). The yeast genomic deletion mutants were first used in the global study of genetic interactions with TOR (Chan et al. 2000). TOR is a highly conserved ataxia telangiectasia-related protein kinase essential for cell growth. To establish a global genetic interaction network of TOR, Chan et al. systematically measured the sensitivity of individual yeast mutants to a low concentration of rapamycin based on the relative growth of each mutant, thereby assembling a global genetic interaction network for TOR. The genome-wide screen is obviously advantageous, because it profiles every single mutant gene, regardless of the severity of the mutants' phenotypes. Even a moderate sensitivity could be biologically significant, which would likely be missed in a traditional genetic screen due to a weak phenotype. Moreover, every single mutation is a complete deletion - it avoids many complicated phenotypes by a point mutation or multi-allelic mutations in a typical traditional genetic screen.

\section{Conclusion}

Chemical ligands can be readily integrated with many existing genomic tools to create assorted chemical genomics approaches such as gene expression and protein profiling, and global analysis of genetic interaction. When combined, these approaches can produce complete biochemical and genetic profiles of the drug target protein. Computationally assisted parallel comparison and cross examination of different profiles will allow accurate detailed prediction and assembly of the biological pathways involved, which form the basis for validation and further detailed study using conventional molecular and cellular approaches. It has become apparent that such global knowledge of the cellular network of genes and proteins is critical for understanding disease mechanisms and selecting the most relevant protein targets for discovery of the optimal drugs. It will also vastly improve our ability to predict other benefits and side effects of the existing drugs, based on the global effects of the drug on gene expression, 
protein posttranslational modifications, and the biological pathways assembled based on various chemical genomics approaches. For instance, global study of genetic interactions can unravel the genetic basis for drug sensitivity. It is well known that some cancer cells are more resistant or prone to certain anti-cancer drugs. One of the determining factors of drug sensitivity is genetic variation in genes in the same biological pathway(s) as the drug target. Some mutations can increase or decrease rapamycin sensitivity by as much as 10,000-fold (Chan et al. 2000). Mutations in yeast DNA repair and checkpoint pathways have also significant altered sensitivity to 23 different anti-cancer compounds (Simon et al. 2000). Drug sensitivity profiles of different types of cancers can be developed based on relative expression of genes involved in biological pathway(s) the drug interferes with. They should be valuable to devise customized protocols for effective treatment of individual cancers. In addition, many hypersensitive genes, genes with significant altered expression or proteins with different modification may be used as direct or secondary drug targets. Inhibition of the secondary targets can sensitize cells to the original drug, thereby significantly decreasing the dosages of the drugs to minimize side effects while achieving maximal therapeutic values. We foresee that chemical ligands should become available for any given protein, which allows chemical modulation of the protein's activity, both positively or negatively, and completely or selectively. These chemical ligands can equip us with the ultimate power to examine every molecular detail of cellular and organismic physiology, which, in turn, can also facilitate the understanding of disease mechanisms, the discovery of highly specific drugs and the devising of customized clinical protocols to treat individual disease conditions.

\section{Acknowledgement}

We thank J. Carvalho for reading the manuscript. This work was supported by grants from National Cancer Institute and American Diabetes Association.

\section{References}

Alaimo, P.J., M.A. Shogren_Knaak, and K.M. Shokat. 2001. Chemical genetic approaches for the elucidation of signaling pathways. Curr Opin Chem Biol 5: 360-7.

Alberts, A.W., J. Chen, G. Kuron, V. Hunt, J. Huff, C. Hoffman, J. Rothrock, M. Lopez, H. Joshua, E. Harris, A. Patchett, R. Monaghan, S. Currie, E. Stapley, G. AlbersSchonberg, O. Hensens, J. Hirshfield, K. Hoogsteen, J. Liesch, and J. Springer. 1980. Mevinolin: a highly potent competitive inhibitor of hydroxymethylglutaryl-coenzyme A reductase and a cholesterol-lowering agent. Proc Natl Acad Sci U S A 77: 3957-61.

Amara, J.F., T. Clackson, V.M. Rivera, T. Guo, T. Keenan, S. Natesan, R. Pollock, W. Yang, N.L. Courage, D.A. Holt, and M. Gilman. 1997. A versatile synthetic dimerizer for the regulation of protein-protein interactions. Proc Natl Acad Sci U S A 94: 10618-23.

Aravind, L., V.M. Dixit, and E.V. Koonin. 2001. Apoptotic molecular machinery: vastly increased complexity in vertebrates revealed by genome comparisons. Science 291: 1279-84.

Bargmann, C.I. 2001. High-throughput reverse genetics: RNAi screens in Caenorhabditis elegans. Genome Biol 2: REVIEWS1005.1.

Barone, R., R. Barone, M. Arbelot, and M. Chanon. 2001. GASP: a computer program to generate automatically polycyclic structures. Tetrahedron 57: 6035-6042.

Beck, T. and M.N. Hall. 1999. The TOR signaling pathway controls nuclear localization of nutrient-regulated transcriptional factors. Nature 402: 689-692.

Belov, L., O. de_la_Vega, C.G. dos_Remedios, S.P. Mulligan, and R.I. Christopherson. 2001. Immunophenotyping of leukemias using a cluster of differentiation antibody microarray. Cancer Res 61: 44839.

Belshaw, P., G. Crabtree, and S. Schreiber. 1996. Controlling Programmed Cell Death with a CyclophilinCyclosporin-Based Chemical Inducer of dimerization. Chemistry \& Biology 3: 731-738.

Bernstein, B.E., J.K. Tong, and S.L. Schreiber. 2000. Genomewide studies of histone deacetylase function in yeast. Proc Natl Acad Sci U S A 97: 13708-13.

Bertram, P.G., J. Choi, J. Carvalho, W.D. Ai, C.B. Zeng, T.F. Chan, and X.F.S. Zheng. 2000. Tripartite regulation of Gln3p by TOR, Ure2p and phosphatases. J. Biol. Chem. 275: 35727-33.

Bishop, A., O. Buzko, S. Heyeck-Dumas, I. Jung, B. Kraybill, Y. Liu, K. Shah, S. Ulrich, L. Witucki, F. Yang, C. Zhang, and K.M. Shokat. 2000. Unnatural ligands for engineered proteins: new tools for chemical genetics. Annu Rev Biophys Biomol Struct 29: 577-606.

Bishop, A.C., K. Shah, Y. Liu, L. Witucki, C. Kung, and K.M. Shokat. 1998. Design of allele-specific inhibitors to probe protein kinase signaling. Current Biology 8: 25766.

Brachmann, R.K., K. Yu, Y. Eby, N.P. Pavletich, and J.D. Boeke. 1998. Genetic selection of intragenic suppressor mutations that reverse the effect of common p53 cancer mutations. Embo J 17: 1847-59.

Brenner, S.E. 2000. Target selection for structural genomics. Nat Struct Biol 7: 967-9.

Brown, E.J., M.W. Albers, T.B. Shin, K. Ichikawa, C.T. Keith, W.S. Lane, and S.L. Schreiber. 1994. A mammalian protein targeted by $\mathrm{G} 1$-arresting rapamycin-receptor complex. Nature 369: 756-8.

Bull, A.T., A.C. Ward, and M. Goodfellow. 2000. Search and discovery strategies for biotechnology: the paradigm shift. Microbiology and Molecular Biology Reviews 64: 573-606.

Burley, S.K. 2000. An overview of structural genomics. Nat Struct Biol 7: 932-4.

Cafferkey, R., P.R. Young, M.M. McLaughlin, D.J. Bergsma, Y. Koltin, G.M. Sathe, L. Faucette, W.K. Eng, R.K. Johnson, and G.P. Livi. 1993. Dominant missense mutations in a novel yeast protein related to mammalian phosphatidylinositol 3-kinase and VPS34 abrogate rapamycin cytotoxicity. Molecular and Cellular Biology 13: 6012-23.

Cardenas, M., N. Cutler, M. Lorenz, C. Di Como, and J. Heitman. 1999. The TOR signaling cascade regulates 
gene expression in response to nutrients. Genes Dev. 13: 3271-79.

Chan, T.F., J. Carvalho, L. Riles, and X.F.S. Zheng. 2000. A chemical genomics approach toward understanding the global functions of TOR. Proc. Natl. Acad. Sci. USA 97: 13227-13232.

Chong, B.E., R.L. Hamler, D.M. Lubman, S.P. Ethier, A.J. Rosenspire, and F.R. Miller. 2001. Differential screening and mass mapping of proteins from premalignant and cancer cell lines using nonporous reversed-phase HPLC coupled with mass spectrometric analysis. Analytical Chemistry 73: 1219-27.

Chung, J., C.J. Kuo, G.R. Crabtree, and J. Blenis. 1992. Rapamycin-FKBP specifically blocks growth-dependent activation of and signaling by the $70 \mathrm{kd} \mathrm{S6}$ protein kinases. Cell 69: 1227-36.

Coelho, P.S., A. Kumar, and M. Snyder. 2000. Genomewide mutant collections: toolboxes for functional genomics. Curr Opin Microbiol 3: 309-15.

Crews, C.M. and U. Splittgerber. 1999. Chemical genetics: exploring and controlling cellular processes with chemical probes. Trends Biochem Sci 24: 317-20.

da Rocha, A., R. Lopes, and G. Schwartsmann. 2001. Natural products in anticancer therapy. Current Opinion in Pharmacology 1: 364-369.

DeDecker, B.S. 2000. Allosteric drugs: thinking outside the active-site box. Chem Biol 7: R103-7.

Fenteany, G. and S.L. Schreiber. 1998. Lactacystin, proteasome function, and cell fate. J Biol Chem 273: 8545-8.

Fenteany, G., R.F. Standaert, W.S. Lane, S. Choi, E.J. Corey, and S.L. Schreiber. 1995. Inhibition of proteasome activities and subunit-specific amino-terminal threonine modification by lactacystin. Science 268: 726-31.

Foster, B.A., H.A. Coffey, M.J. Morin, and F. Rastinejad. 1999. Pharmacological rescue of mutant p53 conformation and function. Science 286: 2507-10.

Frank, R., W. Heikens, G. Heisterberg_Moutsis, and H. Blocker. 1983. A new general approach for the simultaneous chemical synthesis of large numbers of oligonucleotides: segmental solid supports. Nucleic Acids Research 11: 4365-77.

Geysen, H.M., R.H. Meloen, and S.J. Barteling. 1984. Use of peptide synthesis to probe viral antigens for epitopes to a resolution of a single amino acid. Proceedings of the National Academy of Sciences of the United States of America 81: 3998-4002.

Giaccia, A. and M. Kastan. 1998. The complexity of p53 modulation: emerging patterns from divergent signals. Genes Dev. 12: 2973-2983.

Giaever, G., D.D. Shoemaker, T.W. Jones, H. Liang, E.A. Winzeler, A. Astromoff, and R.W. Davis. 1999. Genomic profiling of drug sensitivities via induced haploinsufficiency. Nat Genet 21: 278-83.

Gray, N.S. 2001. Combinatorial libraries and biological discovery. Curr Opin Neurobiol 11: 608-14.

Gygi, S.P. and R. Aebersold. 2000. Mass spectrometry and proteomics. Curr Opin Chem Biol 4: 489-494.

Haab, B.B., M.J. Dunham, and P.O. Brown. 2001. Protein microarrays for highly parallel detection and quantitation of specific proteins and antibodies in complex solutions.
Genome Biol 2: RESEARCH0004.

Harbour, J.W. and D.C. Dean. 2000. The Rb/E2F pathway: expanding roles and emerging paradigms. Genes Dev 14: 2393-409.

Hardwick, J.S., F. Kuruvilla, J.K. Tong, A.F. Shamji, and S.L. Schreiber. 1999. Rapamycin-modulated transcription defines the subset of nutrient-sensitive signaling pathways directly controlled by the Tor proteins. Proc. Natl. Acad. Sci. USA 96: 14866-70.

Hershko, A. and A. Ciechanover. 1998. THE UBIQUITIN SYSTEM. Annu Rev Biochem 67: 425-479.

Hochstrasser, M. 2000. Evolution and function of ubiquitinlike protein-conjugation systems. Nat Cell Biol 2: E1537.

Huang, R.P. 2001. Detection of multiple proteins in an antibody-based protein microarray system. Journal of Immunological Methods 255: 1-13.

Hughes, T.R., M.J. Marton, A.R. Jones, C.J. Roberts, R. Stoughton, C.D. Armour, H.A. Bennett, E. Coffey, H. Dai, Y.D. He, M.J. Kidd, A.M. King, M.R. Meyer, D. Slade, P.Y. Lum, S.B. Stepaniants, D.D. Shoemaker, D. Gachotte, K. Chakraburtty, J. Simon, M. Bard, and S.H. Friend. 2000. Functional discovery via a compendium of expression profiles. Cell 102: 109-26.

Hunter, T. 2000. Signalling-2000 and beyond. Cell 100: 113-127.

Hutt, A.J. and J. O'Grady. 1996. Drug chirality: a consideration of the significance of the stereochemistry of antimicrobial agents. J Antimicrob Chemother 37: 732.

Illgen, K., T. Enderle, C. Broger, and L. Weber. 2000. Simulated molecular evolution in a full combinatorial library. Chem Biol 7: 433-41.

Klebe, G. 2000. Recent developments in structure-based drug design. J Mol Med 78: 269-81.

Knockaert, M., N. Gray, E. Damiens, Y.T. Chang, P. Grellier, K. Grant, D. Fergusson, J. Mottram, M. Soete, J.F. Dubremetz, K. Le_Roch, C. Doerig, P. Schultz, and L. Meijer. 2000. Intracellular targets of cyclin-dependent kinase inhibitors: identification by affinity chromatography using immobilised inhibitors. Chemistry and Biology 7: 411-22.

Kunz, J., R. Henriquez, U. Schneider, M. Deuter-Reinhard, N.R. Movva, and M.N. Hall. 1993. Target of rapamycin in yeast, TOR2, is an essential phosphatidylinositol kinase homolog required for G1 progression. Cell 73: 585-96.

Kuo, C.J., J. Chung, D.F. Fiorentino, W.M. Flanagan, J. Blenis, and G.R. Crabtree. 1992. Rapamycin selectively inhibits interleukin-2 activation of p70 S6 kinase. Nature 358: 70-3.

Lewin, B. 1997. Genes are mutable units (Chapter 3). In Gene VI, pp. 66. Oxford University Press, New York, NY. Liu, L.X., J.M. Spoerke, E.L. Mulligan, J. Chen, B. Reardon, B. Westlund, L. Sun, K. Abel, B. Armstrong, G. Hardiman, J. King, L. McCague, M. Basson, R. Clover, and C.D. Johnson. 1999. High-throughput isolation of Caenorhabditis elegans deletion mutants. Genome Res 9: 859-67.

Lockhart, D.J. and E.A. Winzeler. 2000. Genomics, gene expression and DNA arrays. Nature 405: 827-36.

Lueking, A., M. Horn, H. Eickhoff, K. Bussow, H. Lehrach, 
and G. Walter. 1999. Protein microarrays for gene expression and antibody screening. Anal Biochem 270: 103-11.

MacBeath, G., A. Koehler, and S. Schreiber. 1999. Printing small molecules as microarrays and detecting proteinligand interactions en masse. J Am Chem Soc 121: 79677968.

MacBeath, G. and S.L. Schreiber. 2000. Printing proteins as microarrays for high-throughput function determination [see comments]. Science 289: 1760-3.

Martel, R.R., J. Klicius, and S. Galet. 1977. Inhibition of the immune response by rapamycin, a new antifungal antibiotic. Canadian Journal of Physiology and Pharmacology 55: 48-51.

Mayer, R.J. 2000. The meteoric rise of regulated intracellular proteolysis. Nat Rev Mol Cell Biol 1: 145-8.

Mayer, T.U., T.M. Kapoor, S.J. Haggarty, R.W. King, S.L. Schreiber, and T.J. Mitchison. 1999. Small molecule inhibitor of mitotic spindle bipolarity identified in a phenotype-based screen. Science 286: 971-4.

Moller, A., M. Soldan, U. Volker, and E. Maser. 2001. Twodimensional gel electrophoresis: a powerful method to elucidate cellular responses to toxic compounds. Toxicology 160: 129-138.

Newton, A.C. 1997. Regulation of protein kinase C. Current Opinion in Cell Biology 9: 161-7.

O'Brien, S.J., M. Menotti-Raymond, W.J. Murphy, W.G. Nash, J. Wienberg, R. Stanyon, N.G. Copeland, N.A. Jenkins, J.E. Womack, and J.A. Marshall Graves. 1999. The promise of comparative genomics in mammals. Science 286: 458-62, 479-81.

Oda, Y., T. Nagasu, and B.T. Chait. 2001. Enrichment analysis of phosphorylated proteins as a tool for probing the phosphoproteome. Nat Biotechnol 19: 379-82.

Omura, S., T. Fujimoto, K. Otoguro, K. Matsuzaki, R. Moriguchi, H. Tanaka, and Y. Sasaki. 1991. Lactacystin, a novel microbial metabolite, induces neuritogenesis of neuroblastoma cells. J Antibiot (Tokyo) 44: 113-6.

Rice, J.C. and C.D. Allis. 2001. Histone methylation versus histone acetylation: new insights into epigenetic regulation. Current Opinion in Cell Biology 13: 263-73.

Rubin, G.M., M.D. Yandell, J.R. Wortman, G.L. Gabor Miklos, C.R. Nelson, I.K. Hariharan, M.E. Fortini, P.W. Li, R. Apweiler, W. Fleischmann, J.M. Cherry, S. Henikoff, M.P. Skupski, S. Misra, M. Ashburner, E. Birney, M.S. Boguski, T. Brody, P. Brokstein, S.E. Celniker, S.A. Chervitz, D. Coates, A. Cravchik, A. Gabrielian, R.F. Galle, W.M. Gelbart, R.A. George, L.S. Goldstein, F. Gong, P. Guan, N.L. Harris, B.A. Hay, R.A. Hoskins, J. Li, Z. Li, R.O. Hynes, S.J. Jones, P.M. Kuehl, B. Lemaitre, J.T. Littleton, D.K. Morrison, C. Mungall, P.H. O'Farrell, O.K. Pickeral, C. Shue, L.B. Vosshall, J. Zhang, Q. Zhao, X.H. Zheng, and S. Lewis. 2000. Comparative genomics of the eukaryotes. Science 287: 2204-15.

Russell, R. and D. Eggleston. 2000. New roles for structure in biology and drug discovery. Nature Struct Biol Struct genomics suppl: 928-930.

Sabatini, D.M., H. Erdjument-Bromage, M. Lui, P. Tempst, and S.H. Snyder. 1994. RAFT1: a mammalian protein that binds to FKBP12 in a rapamycin-dependent fashion and is homologous to yeast TORs. Cell 78: 35-43.
Sabers, C.J., M.M. Martin, G.J. Brunn, J.M. Williams, F.J. Dumont, G. Wiederrecht, and R.T. Abraham. 1995. Isolation of a protein target of the FKBP12-rapamycin complex in mammalian cells. Journal of Biological Chemistry 270: 815-22.

Schreiber, S. 2000. Target-oriented and diversity-oriented organic synthesis in drug discovery. Science 287: 19641969.

Schreiber, S.L. 1991. Chemistry and biology of the immunophilins and their immunosuppressive ligands. Science 251: 283-7.

Schreiber, S.L. 1998. Chemical genetics resulting from a passion for synthetic organic chemistry. Bioorganic and Medicinal Chemistry 6: 1127-52.

Shah, K., Y. Liu, C. Deirmengian, and K.M. Shokat. 1997. Engineering unnatural nucleotide specificity for Rous sarcoma virus tyrosine kinase to uniquely label its direct substrates. Proc Natl Acad Sci U S A 94: 3565-70.

Simon, J.A., P. Szankasi, D.K. Nguyen, C. Ludlow, H.M. Dunstan, C.J. Roberts, E.L. Jensen, L.H. Hartwell, and S.H. Friend. 2000. Differential toxicities of anticancer agents among DNA repair and checkpoint mutants of Saccharomyces cerevisiae. Cancer Res 60: 328-33.

Singh, J., M.A. Ator, E.P. Jaeger, M.P. Allen, D.A. Whipple, J.E. Soloweij, S. Chowdhary, and A.M. Treasurywala. 1996. Application of genetic algorithms to combinatorial synthesis: a computational approach to lead identification and lead optimization. Journal of the American Chemical Society 118: 1669-1676.

Spencer, D.M., T.J. Wandless, S.L. Schreiber, and G.R. Crabtree. 1993. Controlling signal transduction with synthetic ligands. Science 262: 1019-24.

Spradling, A.C., D. Stern, A. Beaton, E.J. Rhem, T. Laverty, N. Mozden, S. Misra, and G.M. Rubin. 1999. The Berkeley Drosophila Genome Project gene disruption project: Single P-element insertions mutating $25 \%$ of vital Drosophila genes. Genetics 153: 135-77.

Sterner, D.E. and S.L. Berger. 2000. Acetylation of histones and transcription-related factors. Microbiology and Molecular Biology Reviews 64: 435-59.

Stevens, R.C. 2000. High-throughput protein crystallization. Curr Opin Struct Biol 10: 558-63.

Stevens, R.C., S. Yokoyama, and I.A. Wilson. 2001. Global efforts in structural genomics. Science 294: 89-92.

Stockwell, B.R. 2000. Chemical genetics: ligand-based discovery of gene function. Nature Rev Genet 1: 116-25.

Stockwell, B.R., S.J. Haggarty, and S.L. Schreiber. 1999. High-throughput screening of small molecules in miniaturized mammalian cell-based assays involving post-translational modifications. Chem Biol 6: 71-83.

Tatusov, R.L., E.V. Koonin, and D.J. Lipman. 1997. A genomic perspective on protein families. Science 278: 631-7.

Tuerk, C. and L. Gold. 1990. Systematic evolution of ligands by exponential enrichment: RNA ligands to bacteriophage T4 DNA polymerase. Science 249: 505-10.

Venter, J.C. et al. 2001. The sequence of the human genome. Science 291: 1304-51.

Vidal, M. and H. Endoh. 1999. Prospects for drug screening using the reverse two-hybrid system. Trends Biotechnol 17: $374-81$. 
Vuylsteke, A. 2000. Fundamentals of chirality. Acta Anaesthesiol Belg 51: 113-7.

Wall, D.B., M.T. Kachman, S. Gong, R. Hinderer, S. Parus, D.E. Misek, S.M. Hanash, and D.M. Lubman. 2000. Isoelectric focusing nonporous RP HPLC: a twodimensional liquid-phase separation method for mapping of cellular proteins with identification using MALDI-TOF mass spectrometry. Analytical Chemistry 72: 1099-111.

Winzeler, E.A., D.D. Shoemaker, A. Astromoff, H. Liang, K. Anderson, B. Andre, R. Bangham, R. Benito, J.D. Boeke, H. Bussey, A.M. Chu, C. Connelly, K. Davis, F. Dietrich, S.W. Dow, M. El Bakkoury, F. Foury, S.H. Friend, E. Gentalen, G. Giaever, J.H. Hegemann, T. Jones, M. Laub, H. Liao, R.W. Davis, and e. al. 1999. Functional characterization of the $\mathrm{S}$. cerevisiae genome by gene deletion and parallel analysis. Science 285: 901-6.

Zhu, H., J.F. Klemic, S. Chang, P. Bertone, A. Casamayor, K.G. Klemic, D. Smith, M. Gerstein, M.A. Reed, and M. Snyder. 2000. Analysis of yeast protein kinases using protein chips. Nature Genet 26: 283-9. 


\section{Further Reading}

Caister Academic Press is a leading academic publisher of advanced texts in microbiology, molecular biology and medical research. Full details of all our publications at caister.com

- MALDI-TOF Mass Spectrometry in Microbiology Edited by: M Kostrzewa, S Schubert (2016) www.caister.com/malditof

- Aspergillus and Penicillium in the Post-genomic Era Edited by: RP Vries, IB Gelber, MR Andersen (2016) www.caister.com/aspergillus2

- The Bacteriocins: Current Knowledge and Future Prospects Edited by: RL Dorit, SM Roy, MA Riley (2016)

www.caister.com/bacteriocins

- Omics in Plant Disease Resistance Edited by: V Bhadauria (2016) www.caister.com/opd

- Acidophiles: Life in Extremely Acidic Environments Edited by: R Quatrini, DB Johnson (2016) www.caister.com/acidophiles

- Climate Change and Microbial Ecology: Current Research and Future Trend

Edited by: J Marxsen (2016)

www.caister.com/climate

- Biofilms in Bioremediation: Current Research and Emerging Technologies

Edited by: G Lear (2016)

www.caister.com/biorem

- Microalgae: Current Research and Applications Edited by: MN Tsaloglou (2016) www.caister.com/microalgae

- Gas Plasma Sterilization in Microbiology: Theory, Applications, Pitfalls and New Perspectives Edited by: H Shintani, A Sakudo (2016) www.caister.com/gasplasma

- Virus Evolution: Current Research and Future Directions Edited by: SC Weaver, M Denison, M Roossinck, et al. (2016) www.caister.com/virusevol

- Arboviruses: Molecular Biology, Evolution and Control Edited by: N Vasilakis, DJ Gubler (2016) www.caister.com/arbo

- Shigella: Molecular and Cellular Biology Edited by: WD Picking, WL Picking (2016) www.caister.com/shigella

-Aquatic Biofilms: Ecology, Water Quality and Wastewater Treatment

Edited by: AM Romaní, H Guasch, MD Balaguer (2016)

www.caister.com/aquaticbiofilms

- Alphaviruses: Current Biology

Edited by: S Mahalingam, L Herrero, B Herring (2016)

www.caister.com/alpha

- Thermophilic Microorganisms

Edited by: F Li (2015)

www.caister.com/thermophile
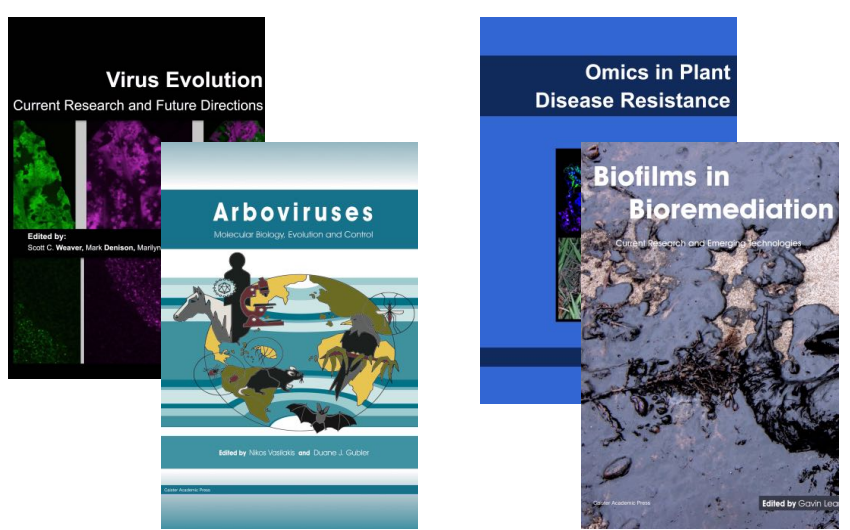
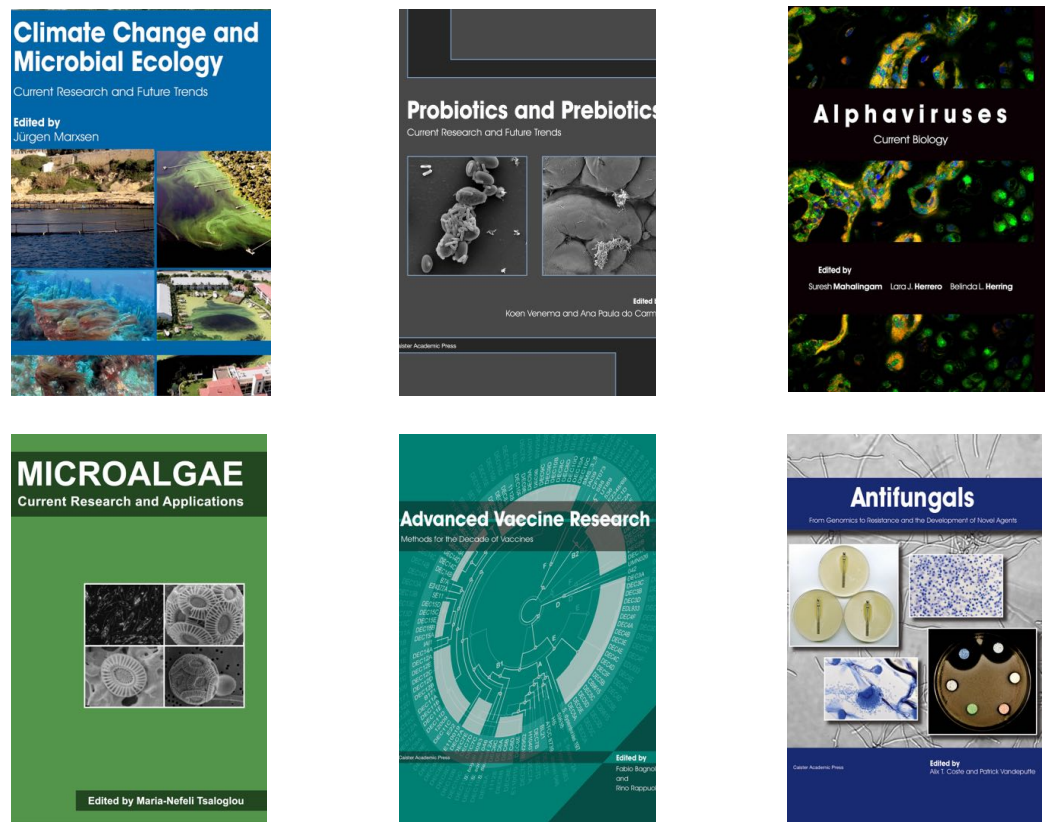

- Flow Cytometry in Microbiology: Technology and Applications Edited by: MG Wilkinson (2015) www.caister.com/flow

- Probiotics and Prebiotics: Current Research and Future Trends Edited by: K Venema, AP Carmo (2015) www.caister.com/probiotics

- Epigenetics: Current Research and Emerging Trends Edited by: BP Chadwick (2015) www.caister.com/epigenetics2015

- Corynebacterium glutamicum: From Systems Biology to Biotechnological Applications

Edited by: A Burkovski (2015)

www.caister.com/cory2

- Advanced Vaccine Research Methods for the Decade of Vaccines

Edited by: F Bagnoli, R Rappuoli (2015)

www.caister.com/vaccines

- Antifungals: From Genomics to Resistance and the Development of Novel Agents

Edited by: AT Coste, P Vandeputte (2015)

www.caister.com/antifungals

- Bacteria-Plant Interactions: Advanced Research and Future Trends Edited by: J Murillo, BA Vinatzer, RW Jackson, et al. (2015) www.caister.com/bacteria-plant

\section{- Aeromonas}

Edited by: J Graf (2015)

www.caister.com/aeromonas

- Antibiotics: Current Innovations and Future Trends

Edited by: S Sánchez, AL Demain (2015)

www.caister.com/antibiotics

- Leishmania: Current Biology and Contro Edited by: S Adak, R Datta (2015) www.caister.com/leish2

- Acanthamoeba: Biology and Pathogenesis (2nd edition) Author: NA Khan (2015)

www.caister.com/acanthamoeba2

- Microarrays: Current Technology, Innovations and Applications Edited by: Z He (2014)

www.caister.com/microarrays2

- Metagenomics of the Microbial Nitrogen Cycle: Theory, Methods and Applications

Edited by: D Marco (2014)

www.caister.com/n2 